\title{
Saving lives in road traffic-ethical aspects
}

\author{
Jessica Nihlén Fahlquist
}

Received: 19 September 2008 / Accepted: 5 March 2009/Published online: 9 April 2009

(C) The Author(s) 2009. This article is published with open access at Springerlink.com

\begin{abstract}
Aim This article aims at giving an overview of five ethical problem areas relating to traffic safety, thereby providing a general framework for analysing traffic safety from an ethical perspective and encouraging further discussion concerning problems, policies and technology in this area. Subjects and methods The problems presented in the article are criminalisation, paternalism, privacy, justice and responsibility, and the reasons for choosing these are the following. First, they are all important areas in moral philosophy. Second, they are fairly general and it should be possible to categorise more specific problems under these headings. Ethical aspects of road traffic have not received the philosophical attention they deserve. Every year, more than 1 million people die globally in traffic accidents, and 20 to 50 million people are injured. Ninety per cent of the road traffic fatalities occur in low- and middle-income countries, where it is a growing problem. Politics, economics, culture and technology affect the number of fatalities and injuries, and the measures used to combat deaths in traffic as well as the role of road traffic should be ethically scrutinised. The topics are analysed and discussed from a moralphilosophical perspective, and the discussion includes both theory and applications.

Results and conclusion The author concludes with some thoughts on how the ethical discussion can be included in
\end{abstract}

J. Nihlén Fahlquist

Department of Philosophy, Delft University of Technology,

P.O. Box 5015, 2600 GA Delft, The Netherlands

J. Nihlén Fahlquist $(\bowtie)$

Division of Philosophy, Royal Institute of Technology,

Teknikringen 78B,

SE-100 44 Stockholm, Sweden

e-mail: j.a.nihlen-fahlquist@tudelft.nl the public debate on how to save lives in road traffic. People in industrialised societies are so used to road traffic that it is almost seen as part of nature. Consequently, we do not acknowledge that we can introduce change and that we can affect the role we have given road traffic and cars. By acknowledging the ethical aspects of road traffic and illuminating the way the choices society makes are ethically charged, it becomes clear that there are alternative ways to design the road traffic system. The most important general conclusion is that discussion concerning these alternative ways of designing the system should be encouraged.

Keywords Traffic safety · Ethics · Criminalisation · Paternalism $\cdot$ Privacy $\cdot$ Risk $\cdot$ Justice $\cdot$ Responsibility

\section{Introduction}

In the month of September 2001, more people died in car crashes in the United States than in the terrorist attacks (Husak 2004). Every year, more than 1 million people die globally in road crashes, and 20 to 50 million people are injured. Ninety per cent of the road traffic fatalities occur in low- and middle-income countries, where it is a growing problem. Road traffic accidents are the ninth leading cause of disease in the world (Peden et al. 2004). In spite of the gravity of the problem of traffic fatalities, it is seldom discussed as an ethical problem or as giving rise to ethical questions. It is the aim of this paper to provide a general overview of ethical aspects of traffic safety, the focus being on the fatalities and injuries road traffic causes and some major ethical aspects of the measures used to save lives.

The main purpose is to show that just as transportation is analysed and discussed from economic, technological, political and geographical perspectives, its ethical dimen- 
sions should be thoroughly and continuously analysed and discussed. Philosophers have not extensively discussed ethical problems relating to transport, although there are some exceptions (Nihlén Fahlquist 2006; Husak 2004; Husak 1994; Zeitler 1997), nor have ethics been comprehensively incorporated in the transportation safety discourse, although there are exceptions (Evans 2008; Evans 2004; Hokstad and Vatn 2008; Elvik 2006; Elvik 1999). In transportation as well as in health care, people die and are prevented from dying due to actions and omissions of individuals as well as functioning and dysfunctional systems and policies. Accordingly, a continuous ethical discussion concerning road traffic is needed. The areas discussed in the following are criminalisation, paternalism, privacy, justice and responsibility. ${ }^{1}$ The reasons for this focus is that these are five important areas in moral philosophy and together they provide a rough list according to which many of the more specific ethically relevant issues arising in traffic safety can be categorised.

\section{Criminalisation}

In the intersection between law and moral philosophy the question arises of what acts should be considered criminal and in need of punishment. Obviously there are a number of acts in road traffic that are criminalised, and there is a constant discussion in many societies about which acts should be punished and how.

There are two major philosophical perspectives on punishment: retributivists argue that we punish because offenders deserve to be punished and consequentialists argue that punishment is justified only if it is likely to have more advantageous consequences than refraining from punishing would. The law and public debates about law are often a mix of these two perspectives, and this is the case when it comes to traffic legislation.

Social and cultural beliefs, norms and conventions affect the way people view the severity of different traffic offences. Some of the traffic offences are considered less severe by a majority of people, whereas others are seen as more serious. Speeding is an example of an offence that is often not considered a major breach of the law, even though speeding is said to be one of the most important causes of traffic mortality (Corbett 2000). In spite of this, about 50\% of Swedish car drivers exceed speed limits. High speed contributes substantially to collisions, and the speed that vehicles have in a collision is crucial to the severity of

\footnotetext{
${ }^{1}$ The environmental problems associated with road traffic are not discussed in this particular paper, but it should be acknowledged that they too imply important ethical problems. The focus in this paper is on the prevention of road traffic fatalities and injuries.
}

resulting injuries (Vägverket/Swedish National Road Administration 2005). It is estimated that about 150 lives could be saved in Sweden every year if everyone stopped exceeding the speed limits. ${ }^{2}$ Against this background, the general acceptance of speeding appears quite peculiar. In contrast, drunk driving is considered immoral, and road crashes involving intoxicated drivers resulting in fatality often spur emotionally laden debates concerning how to punish drunk drivers. This example shows that there are conventions about what is right and wrong in road traffic, and these conventions should be questioned in light of what traffic safety researchers find out about the causes of fatalities and injuries. The two philosophical views on punishment become clear when some people suggest long prison sentences and compare driving after drinking to murder, whereas others express their doubts as to whether this is effective, i.e. focussing on the consequences.

An important aim of criminalising an act is to prevent people from performing that act. Whether criminalisation will actually lead to prevention is an empirical question, and it has been argued that this is an often-neglected fact. Schonsheck argues that philosophers and lawyers implicitly assume that if an act is criminalised, people will automatically conform to the new law. In other words, 'prohibition' and 'prevention' are used interchangeably (Schonsheck, 1994). Furthermore, he argues, if we instead talk about criminal prohibition as an attempt to prevent, this forces us to consider failure and alternative ways to prevent the unwanted act. The discussion of whether to criminalise a certain act must take the consequences of enactment and enforcement as well as side effects and costs into account (Schonsheck 1994).

To illustrate, consider driving under the influence of alcohol. This is an offence in most countries, and it is sometimes argued that a case of drunk driving resulting in a fatality should be compared to murder. According to Schonsheck's argument above, even before criminalising driving under the influence of alcohol we ought to consider alternative ways and carefully analyse whether criminalising the act of drunk driving is the most effective way to achieve this result. One alternative method for managing the problem of drunk driving is the so-called alcohol interlock. This is a device that makes it impossible to drive after drinking. The driver has to prove her sobriety through an exhalation sample before starting the car. The interlock is connected to the car's ignition, and if the measured level is above the maximum level set, the car will not start. Obviously, to force all vehicles to install such a device represents a completely different way of dealing with drunk driving and is likely to meet substantial resistance.

\footnotetext{
${ }^{2}$ The road traffic death toll in Sweden is about 400-500 lives a year.
} 
Moreover, potential ethical aspects of mandatory alcohol interlocks should be addressed (Grill and Nihlén Fahlquist, forthcoming). The point is that there are different ways of solving the problem of drunk driving, and criminalisation is one of several methods. Before criminalising an act, or when confronting the question of whether to make the punishment more severe than previously, alternative methods should be discussed before a decision is made. If it is possible to solve a problem like drunk driving without raising the penalties or criminalising more acts, we should at least consider these other methods and treat them as potential alternatives.

The argument above is, of course, a consequentialist one. However, we do not punish solely to prevent unwanted actions. Drunk driving may be criminalised and punished because it is simply seen as morally wrong to risk people's lives by drinking and driving. Douglas Husak, who sets out to determine the seriousness of drunk driving, has discussed this line of thought. The idea is that the offender should be punished in proportion to her desert, which is a function of how serious the offence is (Husak 1994). According to Husak, drunk driving per se is not a very serious crime, but a hierarchy of drunk driving offences should be created that distinguishes between aggravated drunk driving, which is considered a serious offence, and ordinary drunk driving, which is not. Whereas ordinary drunk driving does not create a substantially higher risk of injury compared to sober driving, drunk driving with BAC $0.2 \%$ does (Husak 1994).

\section{Paternalism}

Accusations of paternalism are common in the history of traffic safety debates, for example, about the mandatory use of seatbelts, bicycle helmets and motorcycle helmets. It is argued that individual freedom and responsibility are diminished when people are not allowed to decide for themselves whether to accept a certain risk.

There are two major justifications for laws requiring people to use such potentially liberty-limiting devices. First, there is an economic incentive to reduce the costs of saving lives and rehabilitating people. Second, and more controversial, it may be argued that people should be forced to, for example, use a seatbelt for their own good.

Mill, in his famous defence of anti-paternalism, asserts that the only justified interference with the liberty of individuals is that which is aimed at protecting other individuals from harm, the so-called Harm Principle (Mill 1985). Since then, many theorists have contributed to the debate on paternalism.

It is possible to argue for the mandatory use of seatbelts from a paternalistic viewpoint or merely from an economic perspective or to combine the two. The proponent of paternalism has two potential justifications for such a law, namely the cost to others and the harm to the individual not using a seatbelt (Schonsheck 1994). The only liberal argument for such a law is to point at the economic cost for others created by those not using a seatbelt (Schonsheck 1994). The discussion on the potentially paternalistic justification for seatbelts is only applicable to the driver, since the driver can be said to be responsible for not harming her passengers. It could be argued that requiring the driver to make sure that her passengers use seatbelts is an implication of the Harm Principle rather than an instance of paternalism. It has been suggested that accepting Mill's anti-paternalist view does not necessarily entail refraining from interfering with activities like driving with unbelted passengers (Hansson 2006).

As argued by Dworkin concerning the law requiring motorcyclists to wear a helmet, if the economic cost is the only reason to require helmets, that could be achieved by requiring that motorcyclists purchase a medical insurance to cover that cost as a condition for licensing (Dworkin 1983). Because motorcycling is such a risky activity and the law requiring motorcyclists to wear a helmet appears to be quite a reasonable law, it has been said to be an "embarrassment" to the liberal and to make the strongest case for hard paternalism (Feinberg 1986).

Often, in real cases, it is not completely clear whether potentially paternalistic measures are introduced purely for paternalistic reasons or because of the societal costs associated with not implementing the new policy. Discussions concerning potentially liberty-limiting devices will surely continue to arise in the context of traffic safety. However, road traffic is very different from, for example, smoking in that driving a car exposes others to substantial risks. The best defence for making alcohol interlocks mandatory in all cars, for instance, is probably that the driver who drinks before driving her car exposes others to a substantial risk. A smoker who does not smoke outside her own free-standing house does not directly cause harm to others, so a prohibition on smoking would arguably be more paternalistic than a law on alcohol interlocks.

\section{Privacy}

During the twentieth century, car driving became a central feature of the social, economic and cultural development of the Western world. Culturally, it is strongly associated with the values of autonomy, independence and freedom of movement. Surely, this is one important reason for the unwillingness of people to be exposed to surveillance cameras and other kinds of control of their driving. There is 
an inherent tension in the conception of road traffic between the idea of a freedom of movement and an accessible transportation system on the one hand and safety on the other. We want to be able to move freely without restrictions, but we also want to be safe. Those who argue that privacy is merely a prima facie right could possibly argue that safety is a more fundamental value, whereas those embracing a more liberal approach would advocate the value of individual freedom and privacy. The association between the automobile and such values is very strong. It has even been argued that "automobility" complements autonomy and that automobiles enhance privacy (Lomasky 1997).

Due to technological development there are a number of new possibilities that either force road users, primarily car drivers, to behave in a certain way to increase safety or that control the behaviour of road users. Alcohol interlocks are an example of the former and surveillance cameras an example of the latter. The development of information technology provides helpful tools that can be used to enhance safety, but sometimes at the possible expense of the privacy of individuals. Vehicle safety technology has been developed with the aim to connect vehicles with roadside infrastructure, and this is likely to have substantial safety benefits, but also to increase the risk of extensive surveillance (Zimmer 2005). This raises questions concerning the problem of "privacy in public". Nissenbaum argues that although lawyers and philosophers have discussed privacy frequently, the focus has been on personal and sensitive information. The problem today is that a large part of the information that can be and is collected is from the previously more or less ignored public sphere. Hence, theories concerning the right to privacy should address the problem of privacy in public (Nissenbaum 1998).

Nissenbaum suggests that the problem of privacy in public should be addressed by conceptualising privacy as "contextual integrity", which essentially means that every context has its own norms of appropriateness and distribution, meaning that what information it is appropriate to share and how this information is to be distributed vary in different contexts (Nissenbaum 2004). Zimmer applies these ideas to highway travel, attempting to establish what the existing norms of appropriateness and distribution are in the context of highway travel. He suggests that while it is considered appropriate to share information that is easily observed, for example, the license plate number, it is not in accordance with existing norms to share information about the identity of the vehicle's occupants. Furthermore, while it is appropriate to share information about license plate numbers, prevailing norms of distribution restrict the ability to receive additional information that is based on the license plate number (Zimmer 2005).
Whereas it is important to take existing norms into consideration, it should be acknowledged that we run the risk of adjusting to less and less privacy, meaning that the existing norms equal what we have come to accept because of this adjustment. We should not merely focus on existing norms, but also on critically examined norms.

With new technology being developed at an impressive rate, there is hope that vehicle and road safety will improve substantially. However, since a considerable part of that new technology entails some form of information gathering, its potential threat to privacy should be acknowledged. What is essentially at issue is how to balance the values of individual liberty and safety. Moreover, is what we do as road users private or public? In the developed part of the world, we are used to having access to a private space when driving a car, and many people drive their cars in order to escape the public sphere for a while. However, against the background of the high number of fatalities and injuries, driving a car is noticeably different than, for example, being in one's home, and it could be questioned whether the private space we now seem to believe we have a right to is reasonable, given the human and economic cost of road traffic. It may not be reasonable to expect the same kind of privacy in our cars as we do in our homes. On the other hand, a considerable number of women die every year due to domestic violence, which would indicate that the argument of people dying is not adequate to defend privacy intrusions in road traffic, but not in our homes. To what extent we should trade privacy for safety is clearly a difficult question, but it is an important ethical question to ask in relation to road traffic.

\section{Justice}

Traditionally, the departments of transport and their related agencies have managed traffic safety. Consequently, mobility has been the main focus with an emphasis on infrastructure and vehicles, neglecting the safety of nonmotorized road users (Peden et al. 2004). This is problematic for several reasons. Children, young adults and the elderly are disproportionately exposed to the risk of being injured or killed in a road crash, especially if they are pedestrians (Malek et al. 1990; Fontaine and Gourlet 1997; Yee et al. 2006). Pedestrians and cyclists are generally exposed to a greater risk than car drivers. Intuitively, there appears to be a morally relevant difference between different groups of road users. ${ }^{3}$ Clearly, there are substantial differences between child pedestrians and risk-seeking

\footnotetext{
${ }^{3}$ A recent survey confirmed that many people have this concern, i.e. that more money should be spent on saving children due to their vulnerability, Hokstad and Vatn (2008), p. 1445.
} 
adults who, for instance, choose to ride a motorcycle after having contemplated the risks of doing that. The problem is how to apply this intuition to policy-making and to what extent. It has recently been argued that fewer resources should be spent on "deliberate traffic offenders" in favour of "innocent" road users, for reasons of fairness (Hokstad and Vatn 2008).

Since vulnerable road users have a high risk exposure and have to use the roads every day, perhaps they should be the primary focus of safety interventions in areas they are unable to avoid. It could be argued that they have a right to move around outside in a way that does not correspond to a right to drive a car. These groups are not merely the most vulnerable, but in addition they sometimes lack the ability to influence infrastructure, and this should be taken into account in policy-making. Acknowledging the differences of risk exposure and the imbalance of power and responsibility between different groups of road users illuminates the following question. For which group of road users is the road system and the infrastructure designed? Partly this is a practical question and a question of how the road transport system has evolved gradually since the introduction of the automobile, but the way the system works today should be analysed from the perspective of justice as well. It has been argued that the modern road transport system primarily is designed for car drivers, for example due to the fact that enormous amounts of money are spent on highways and the safety of automobiles as opposed to walking paths and the safety of pedestrians and cyclists. Moreover, as mentioned above, the automobile has been given priority at the cost of pedestrians, and it has been argued that this should be changed for environmental and public health reasons (Gunnarsson 2005).

If society's resources were unlimited it might be thought imperative to save all road users from dying or being injured in road traffic, or rather that it would be imperative to save as many lives as possible as long as measures to enhance safety do not carry with them an unreasonable "ethical cost" in terms of, for instance, intrusions of privacy. However, resources are limited, and priorities have to be set. The question then becomes how resources should be used.

A common device used to decide whether certain road safety measures should be introduced is cost-benefit analysis, which implies that a measure should be taken if the benefits outweigh the costs, but if the opposite is true it should not. Cost-benefit analysis is "an operational definition of what public policy based on a utilitarian calculus implies" (Elvik 2006). The benefits are often based on the notion of willingness-to-pay (WTP), which refers to the maximum amount of money a person is willing to pay for that benefit. There are a number of problems with WTP, for instance, that wealthy people often are willing to pay more for two reasons. First, the marginal utility of money declines as a function of the wealth, meaning that the difference between 10 and 20 is greater than the difference between 100 and 120 . If a person is wealthy she is likely to be willing to pay more since it does not make a big difference to her financial situation, whereas it could make a big difference for someone who is not as well off. Second, it has been argued that poor people, having to choose more carefully because of lack of resources, may prefer other kinds of benefits at the cost of increased safety (Hokstad and Vatn 2008).

Another concept that is used in this approach is value of statistical life (VSL), which is a monetary measure of the benefits to people from small risk reductions that arise from safety projects (Hokstad and Vatn 2008). Critics have argued that it is not acceptable to put a monetary value on human life (Elvik 2001; Frank 2000; Hansson 2007; Hauer 1994).

Hokstad and Vatn argue that instead of treating utility as the overriding rule for allocation of resources for risk reduction, fairness should be the guiding rule, even if cost-benefit analysis could be one useful tool in the process of arriving at good and fair priorities (Hokstad and Vatn 2008).

Following this line of thought, perhaps additional resources should be spent on vulnerable road users, such as child pedestrians, even if it is not the most cost-efficient way to spend public funds. Instead, there are tendencies to assume that children, the elderly and disabled people have less value than non-disabled grown-ups. The concept of disability-adjusted life year (DALY) is used to compare the burden of disease in different countries. It puts a numerical number on mortality and morbidity and counts the years lost due to premature death and the years lived with disabilities. Different disabilities have different numerical values according to how much they are estimated to affect quality of life. This model has been criticised, and one of the objections to it is that the life year lost for a child or an individual older than 55 is counted less than a life year lost for a grown-up individual under the age of 55. Furthermore, the DALY approach assumes that people with a disability have less quality of life than people who do not have a disability and that people with a disability are less entitled to health resources (Arnesen and Nord 1999). This, of course, goes against the intuition that vulnerable groups should be protected and perhaps even be the standard measure when designing the infrastructure. Moreover, the very assumption that the quality of an individual's life can be measured objectively at all and that the only relevant criterion to judge the quality of an individual's life is whether she has a disability or not and how big of an impairment that particular disability is, from an objective standpoint, raises concern. Surely, most people would be 
offended by the idea that their quality of life is judged by people who do not know them and determined according to an allegedly objective list with numbers attached to disabilities. Moreover, as noticed by Arnesen and Nord, to assume that the healthier a person is the more valuable their life is to themselves and to society is contrary to the Declaration of Human Rights and its basic notion that all people are equal (Arnesen and Nord 1999).

Another problem is how groups with different risk proneness should be treated. For example, motorcyclists have a substantially higher risk of being killed or injured than any other vehicle user (Elliott et al. 2007). It has been estimated that the risk of being injured when travelling by motorcycle is about ten times as high as when travelling by car (Aare and von Holst 1999). The question is whether motorcycling should be seen as a choice to expose oneself to a greater risk and hence something for which one has to bear a larger proportion of responsibility and possibly cost than for driving a car.

There are local and global socio-economic patterns that entail problems of justice. Poor countries and poor people in all countries bear a disproportionate burden of disease and fatalities. Apart from the cost in terms of human suffering, the economic cost is substantial. It has been estimated that the direct cost due to road crashes is about 1-2 per cent of GNP in low- and middle-income countries and that the total cost to these economies is about US\$ 65 billion, which is more than the total annual amount of development assistance they receive (Jacobs et al. 2000; Nantulya and Reich 2003). Furthermore, there is a growing gap between high-income countries and low- and middleincome countries, with the former experiencing improved safety, whereas the latter experience increasing rates of traffic mortality and injuries (Jacobs et al. 2000). Concerning health and safety, studies have shown that socio-economic factors affect the severity of injury (Zambon and Hasselberg 2006). Furthermore, socio-economic differences affect injuries even when individuals from different socio-economic groups drive cars that are equally safe (Laflamme et al. 2005).

The fact that poor people in all countries and regions are exposed to a greater risk is partly due to the fact that they cannot afford to drive a car. Instead, they have to walk, ride a bicycle or motorized two-wheeler or go by public transport. This has implications for the way technology and safety policies are exported from high-income countries. In high-income countries, more car occupants are killed in crashes, which is due to the higher degree of motorization, hence the focus on vehicle safety. Obviously, a focus on vehicle safety would not be the most effective way to reduce the number of fatalities and injuries in countries where vulnerable road users like pedestrians and cyclists are more frequently killed and injured than car occupants (Ameratunga et al. 2006).
The problem of the unequal global burden of road traffic fatalities and injuries is related to the philosophical debate on how theories of distributive justice and human rights should incorporate aspects of health and health care (Daniels 2001). It has been argued that health inequalities are worse than other kinds of inequalities and that health is of special moral importance (Daniels et al. 2004). Furthermore, the concept of health equity should not merely include the distribution of health care, but also the capability to achieve good health (Sen 2004). If I have a right to health or a right not to be killed or severely injured in a car crash when I go to the grocery store to buy some milk, whose duty is it to substantiate that right? Is it the government's duty or, against the background of global inequalities, is it an international duty that should be fulfilled by the United Nations? The concept of a right is not unproblematic in relation to risk exposure. Moral philosophy has traditionally focussed on cases where alternatives for action are given beforehand and where the consequences of these actions are well known. This is often not the case, and whereas a majority of people would agree that killing is wrong, they might be less certain when confronted with a case of exposing someone to a risk of getting killed or injured. Whereas most people would agree that it is not acceptable for me to expose someone else to the risk of being run over by my car if the probability is 1 in 10 , it is less clear whether it is permissible if the risk is 1 in $1,000,000$. (Hansson 2003). If we have an absolute right not to be exposed to the risk of being killed or severely injured by traffic, this would effectively mean that road traffic, in its current shape, would not be allowed. In this case, that right is severely infringed upon everywhere in the world. Most people would probably not approve of such a right since it would dramatically reduce mobility and have serious effects on the economy. So either the concept of a right is not appropriate for road traffic safety or it has to be modified. Perhaps the right could be said to be a right to live in a society where everything that is practically and economically possible has been done to reduce the risk of being killed or severely injured, especially for vulnerable road users. But this becomes a rather vaguely formulated right because it is difficult to determine what "everything that is practically and economically possible" means.

Against the background of the global inequalities in road traffic mortality and injuries, a central question to be addressed is what high-income countries can and should do in order to assist low- and middle-income countries to build infrastructure and vehicles in a way that promotes safety. Although successful strategies in high-income societies could sometimes be transferred, this should be done with caution since the social, cultural and political contexts are different (Nantulya and Reich 2003). 


\section{Responsibility}

Traditionally, driving a car has been seen as associated with the individual and her autonomy and independence. Consequently, accidents have largely been considered an individual responsibility, and a collision has been seen as the result of either unfortunate circumstances or individuals acting wrongly. Increasingly, road safety is instead seen as a joint effort and responsibility as distributed between different actors. Traditionally, the focus of traffic safety policy has been the backward-looking responsibility of the individual road users (Peden et al. 2004). The question has been who caused a road crash, and it has been assumed that if A caused the event E, if someone is worthy of blame for it, it would be $\mathrm{A}$, and $\mathrm{A}$ has been an individual road user. The focus on individual causal responsibility and blameworthiness is probably connected to the assumption that the most important cause of road crashes is human error (Petridou and Moustaki 2000). However, a recent study shows that inadequate road design is the most important cause of people dying in road crashes (Stigsson 2006).

Changing the view of causation may be part of a new emerging perspective on responsibility and traffic safety. In 1997 the Swedish Parliament adopted a governmental bill that introduced the so-called Vision Zero as the long-term goal for all traffic safety projects in the country. It received substantial attention, and critics accused the proponents of setting unrealistic and possibly naïve targets. Vision Zero also entailed a fundamentally new view on responsibility and traffic safety. The so-called system designers (e.g, vehicle-producing companies and road maintainers) were assigned a forward-looking responsibility, and it was said that the most important safety-increasing measure was to improve the systems. Hence, the focus shifted from the individual road user to the system designers and from backward-looking responsibility to forward-looking responsibility. Emphasising the systems also entails a shift of focus from the triggering causal factors to the underlying ones. According to Vision Zero individuals are still responsible for following traffic rules, but if they do not live up to these expectations, the system designers must take measures (Nihlén Fahlquist 2006). ${ }^{4}$

So, what could this mean in practice? As an example, consider a road crash. Let us say that individual A had been

\footnotetext{
${ }^{4}$ Norway adopted Vision Zero in 2001. The "Sustainable Traffic Safety" approach in The Netherlands stresses that the unpredictable and fallible nature of human beings as the weakest link in the transport system should be taken into account as a reason to build safer, sustainable systems to be able to cope with human error [Pieter van Vliet and Govert Schemers (2000) "Sustainable safety" Ministry of Transport, Public Works and Water Management (http://www.rws-avv. nl/pls/portal30/docs/1771.PDF), p. 9]. These are similar examples of a changing perspective focussing more on systemic improvement than individual errors and blame.
}

drinking alcohol previous to her driving. She obviously did not take responsibility, since she did not follow the rules prohibiting drunk driving. Regardless of how we deal with the causal responsibility and potential blame, the system designers are ascribed responsibility in the forward-looking sense. In practice, this could imply legislation on alcohol interlocks, installing an alcohol interlock in her car, etc. This represents a more pragmatic outlook since it asks what the system designers can do about the more general problem of drunk driving, given that many individual road users do not take responsibility. It is a more realistic approach than the previous one because it acknowledges the facts, in this case that people sometimes ignore traffic legislation. Hopefully what we achieve by blaming (and establishing legal liability) $\mathrm{A}$ is that she does not do it again, and if she is also an alcoholic we can hope that she will get help for her disease. However, this does not solve the general problem of drunk driving. To focus on forwardlooking responsibility appears to be an effective approach particularly in cases where there are technological devices, like alcohol interlocks, that can solve that general problem. To what extent the automobile industry should be considered responsible, for example, for how they promote new cars is another important aspect to be taken into account. Wetmore describes a change in perspective in the USA that occurred gradually during the twentieth century. In the first part of the century, drivers were considered to be completely responsible, and safety was perceived as being a matter of collision-avoidance. This was eventually replaced in the $1950 \mathrm{~s}-1960$ s by the so-called crashworthiness approach that emphasised the "second collision", i.e. what happened after the collision in the phase where injuries occur. This conception of safety put focus on the responsibility of automobile producers who, it was argued, should develop technology that protects people inside their cars. They were supposed to compensate for the shortcomings of the drivers, whose errors and mistakes would always be a fact. This perspective redistributed responsibility from the driver to the vehicle and those who develop technology (Wetmore 2004).

When analysing issues of responsibility it is useful to compare road traffic and other modes of transportation, e.g. aviation. The question is how conventions of responsibility distributions have been developed in different areas. It goes without saying that there are differences between road traffic and aviation as modes of transportation and perhaps the different conventions of responsibility are completely justifiable. However, there may also be similarities that should be acknowledged. One of the differences between road traffic and air traffic is that the pilot, besides being the one who flies the plane, is often employed by an airline company and that her passengers in these cases are also customers. This contractual situation has consequences for 
the issue of responsibility. In cases of commercial aviation, the contract between the employer and the employee and the one between the customers/passengers and the pilot as well as the airline affects the distribution of responsibility. The contracts oblige the pilot to take certain safety measures and to adopt a cautious attitude to flying. A question that may be asked is why the explicit pilot-incommand's responsibility which makes the pilot responsible for everyone's, safety on board the aeroplane, does not apply to the car driver.

It is increasingly being acknowledged that road safety is not merely about individual behaviour and that institutional actors should take responsibility in order to decrease the number of fatalities. For example, the European Union has set the target to halve the number of traffic fatalities by 2010 .

\section{Conclusion}

I would like to end this overview of ethical problem areas in traffic safety with some concluding thoughts on how these five ethical topics can be included and inform policy.

\section{Criminalisation}

Attempts should be made to analyse the problem at hand carefully and as open-mindedly as possible before rushing to the conclusion that the best way to reduce or eliminate an unwanted and harmful behaviour is to criminalise and punish. Alternatives should be considered and creativity in problem solving encouraged. A good example is drunk driving where the alcohol interlock is a device worth considering as an alternative or at least additional measure to punishment.

\section{Paternalism}

Most measures to increase safety in road traffic can be motivated by the notion of protecting others against harm, which means that even a liberal can endorse them. However, there are some measures where the most beneficial to society may be to ignore it, for example motorcyclists not wearing a helmet, but where most people still believe society should protect individuals against harm by legislation or technology. It should be acknowledged that this is the case, and it would be helpful to carefully analyse and discuss new measures, keeping in mind the distinction between harming others and harming oneself. In some cases, most people share an intuition that a measure is justifiable even though it is paternalistic, but in other cases paternalistic measures appear unjustifiable. By acknowledging and discussing such issues freely and publicly we make sure that new laws and technologies are at least closer to being ethically justifiable.

\section{Privacy}

There appears to be a fundamental difference between privacy in our own homes and privacy on the road. The reasons we are equally attached to the notion of privacy in our cars as we are to privacy in our homes are tradition, culture and habits. We should recognise that the great degree of riskexposure associated with driving may imply that the expectation of privacy on the road is not reasonable.

Justice

A humane society protects vulnerable human beings. A humane infrastructure protects vulnerable road users, for example children, the elderly and disabled people. This implies that we should not count their lives or the quality of their lives less than others. It may even mean that additional attention should be directed at protecting such groups. A minimal requirement should be that potential damaging effects on vulnerable groups should always be taken into account when planning infrastructural projects.

\section{Responsibility}

The traditional view of responsibility for traffic safety is closely attached to the notion that safety is about individuals driving safely and that accidents are caused by drivers. While this is true to some extent, the emerging view that a major role can and should be played by institutions, for example governments and vehicle-producing companies, is useful and reasonable. The implied notion is that responsibility has to be distributed and shared between different actors if a safer road traffic environment is to be achieved.

People in industrialised societies are so used to road traffic that it is almost considered a part of nature. Consequently, we do not acknowledge that we can introduce change and that we can affect the role we have given road traffic and cars. By acknowledging the ethical aspects of road traffic and illuminating the way the choices society makes are ethically charged, it becomes clear that there are alternative ways to design the road traffic system. The most important general conclusion is that discussion concerning these alternative ways of designing the system should be encouraged. Here are some examples of questions to address in public debates:

- What are the reasons for prohibiting certain behaviour or requiring a certain safety device - to protect the individual from herself, to protect others or to save money? Which of these reasons are valid? 
- Should society criminalise unsafe behaviour or use technology (when possible) to eliminate the unwanted behaviour?

- To what extent is it reasonable to expect privacy on the road?

- Should additional measures be used to protect vulnerable road users?

- Should safety be seen as the result of individuals behaving responsibly or the system designers designing safe systems?

Acknowledgements This article was written when the author carried out research financed by The Swedish Governmental Agency for Innovation Systems (Vinnova) at the Royal Institute of Technology in Stockholm. It was further developed when the author was conducting research at Delft University of Technology for the research program Moral Responsibility in R\&D Networks, which is supported by The Netherlands Organisation for Scientific Research (NWO) under grant no. 360-20-160.

Conflict of interest The author discloses any associations that might pose a conflict of interest.

Open Access This article is distributed under the terms of the Creative Commons Attribution Noncommercial License which permits any noncommercial use, distribution, and reproduction in any medium, provided the original author(s) and source are credited.

\section{References}

Aare M, von Holst H (1999) Injuries from motorcycle and moped crashes in Sweden from 1987 to 1999. Inj Contr Saf Promot 10:131-138. doi:10.1076/icsp.10.3.131.14556

Ameratunga S, Hijar M, Norton R (2006) Road traffic injuries: confronting disparities to address a global health problem. Lancet 367(9521):1533-1540. doi:10.1016/S0140-6736(06)68654-6

Anand S, Peter F, Sen A (eds) (2004) Public health, ethics and equity. Oxford University Press, Oxford

Arnesen T, Nord E (1999) The value of DALY life: problems with ethics and validity of disability adjusted life years. BMJ 27 (319):1423-1425

Corbett C (2000) A typology of drivers' responses to speed cameras: Implications for speed limit enforcement and road safety. Psychol Crime Law 6(4):305-330. doi:10.1080/10683160008409809

Daniels N (2001) Just health care. Cambridge University Press, Cambridge

Daniels N, Kennedy B, Kawachi I (2004) Health and inequality, or, why justice is good for our health. In: Anand S, Peter F, Sen A (eds) Public health, ethics and equity. Oxford University Press, Oxford, pp 63-92

Dworkin G (1983) Paternalism: Some second thoughts. In: Sartorius R (ed) Paternalism. University of Minnesota Press, Minneapolis, pp $105-111$

Elliott MA, Baughan CJ, Sexton BF (2007) Errors and violations in relation to motorcyclists' crash risk. Accident Anal Prev 39 (3):491-499. doi:10.1016/j.aap. 2006.08.012

Elvik R (2001) Cost-benefit analysis of road safety measures: Applicability and controversies. Accident Anal Prev 33(1):917. doi:10.1016/S0001-4575(00)00010-5
Elvik R (1999) Can injury prevention efforts go too far?: Reflections on some possible implications of Vision Zero for road accident fatalities. Accident Anal Prev 31(3):265-286. doi:10.1016/ S0001-4575(98)00079-7

Elvik R (2006) Are individual preferences always a legitimate basis for evaluating the costs and benefits of public policy?: The case of road traffic law enforcement. Transport Policy 13(5):379-385. doi:10.1016/j.tranpol.2006.01.002

Evans L (2004) Traffic safety. Science Serving Society, Bloomfield

Evans L (2008) Death in traffic. Why are the ethical issues ignored? Studies in Ethics, Law and Technology 2(1). doi:10.2202/19416008.1014

Feinberg J (1986) Harm to self. Oxford University Press, Oxford

Fontaine H, Gourlet Y (1997) Fatal pedestrian accidents in France: A typological analysis. Accident Anal Prev 29(3):303-312. doi:10.1016/S0001-4575(96)00084-X

Frank RH (2000) Why is cost-benefit analysis so controversial? J Legal Med 29(2):913-930

Grill K, Nihlén Fahlquist J Responsibility, paternalism and alcohol interlocks. In Dawson A, Donckers H, Maes L (eds) Ethics of health promotion. Forthcoming from Springer

Gunnarsson SO (2005) Strategi för att skapa en gångvänlig och mänsklig stad. Fotgängarnas forening Basun 2005:1, available at http://www.fot.se/admin/editor/files/Rapporter/Basun-blom.pdf Accessed 1 April 2009

Hansson SO (2003) Ethical criteria of risk acceptance. Erkenntnis 59:291-309. doi:10.1023/A:1026005915919

Hansson SO (2006) Extended antipaternalism. J Med Ethics 31:97100. doi:10.1136/jme.2003.005488

Hansson SO (2007) Philosophical problems in cost-benefit analysis. Econ Philos 23:163-183. doi:10.1017/S0266267107001356

Hauer E (1994) Can one estimate the value of life or is it better to be dead than stuck in traffic? Transport Res A-Pol 28(2):109-118. doi:10.1016/0965-8564(94)90032-9

Hokstad P, Vatn J (2008) Ethical dilemmas in traffic safety work. Safety Sci 46:1435-1449. DOI:10.1016/j.ssci.2007.10.006

Husak D (1994) Is drunk driving a serious offense? Philos Public Aff 23(1):52-73. doi:10.1111/j.1088-4963.1994.tb00004

Husak D (2004) Vehicles and crashes: Why is this moral issue overlooked? Soc Theor Pract 30(3):351-370

Jacobs G, Aeron-Thomas A, Astrop A (2000) Estimating global road fatalities. TRL Report 445. Transport Research Laboratory, London

Laflamme L, Vaez M, Hasselberg M, Kullgren A (2005) Car safety and social differences in traffic injuries among young adult drivers: A study of two-car injury-generating crashes in Sweden. Safety Sci 43:1-10. doi:doi:10.1016/j.ssci.2004.09.001

Lomasky LE (1997) Autonomy and automobility, The Independent Review 2(1)

Malek M, Guyer B, Lescohier I (1990) The epidemiology and prevention of child pedestrian injury. Accident Anal Prev 22 (4):301-313. doi:10.1016/0001-4575(90)90046-N

Mill JS (1985) On Liberty. Penguin, London

Nantulya VM, Reich MR (2003) Equity dimensions of road traffic injuries in low- and middle income countries. Inj Contr Saf Promot 10(1-2):13-20. doi:10.1076/icsp.10.1.13.14116

Nihlén Fahlquist J (2006) Responsibility ascriptions and Vision Zero. Accident Anal Prev 38(6):1113-1118. doi:10.1016/j.aap. 2006.04 .020

Nissenbaum H (1998) Protecting privacy in an a information age: The problem with privacy in public. Law Phil 17:559-596

Nissenbaum H (2004) Privacy as contextual integrity. Wash Law Rev 79(1):119-157

Peden M, Scurfield R, Sleet D, Mohan D, Hyder AA, Jarawan E, Mathers C (ed) (2004) World Report on Road Traffic Injury Prevention. World Health Organization 
Petridou E, Moustaki M (2000) Human factors in road traffic crashes. Eur J Epidemiol 16(9):819-826. doi:10.1023/A:1007649804201

Schonsheck J (1994) On Criminalization. An essay in the philosophy of criminal law. Kluwer Academic Press, Dordrecht

Sen A (2004) Why health equity? In: Anand S, Peter F, Sen A. Public Health, Ethics and Equity, (ed) Oxford University Press, Oxford, pp 21-33

Stigsson H (2006) Folksam/Karolinska Institutet (in Swedish), 11 Jan Ekot (Swedish radio news program)

van Vliet P, Schemers G (2000) Sustainable Safety, Ministry of Transport, Public Works and Water Management, The Netherlands. Available at http://www.rws-avv.nl/pls/portal30/docs/1771. PDF. Accessed 8 Dec 2008

Vägverket/Swedish National Road Administration (2005) Vägverket Uppdrag om hastighetsgränser. publication 2005:100
Wetmore J (2004) Redefining risks and redistributing responsibilities: Building networks to increase automobile safety. Science Tech Human Values 29:377-404. doi:10.1177/0162243904264486

Yee WY, Cameron PA, Bailey MJ (2006) Road traffic injuries in the elderly. Bailey EMJ 23(1):42-46. doi:10.1136/emj.2005.023754

Zambon F, Hasselberg M (2006) Socioeconomic differences and motorcycle injuries: Age at risk and injury severity among young drivers. A Swedish nationwide cohort study. Accident Anal Prev 38:1183-1189. doi:10.1016/j.aap.2006.05.005

Zeitler U (1997) Transport ethics. An ethical analysis of the impact of Passenger transport on human and non-human nature. Aarhus University, Aarhus

Zimmer M (2005) Surveillance, privacy and the ethics of vehicle safety communication. Ethics Info Tech 7:201-210. doi:10.1007/ s10676-006-0016-0 